\title{
Изучение Условий извлечения ПАУ из донных отложений при определении методом ВЭЖХ со спектрофрлуориметрическим детектированием
}

\author{
Котова В.Е. ${ }^{1}$, Андреев Ю.А. ${ }^{1,2}$ \\ ${ }^{1}$ ФГБУ «Гидрохимический институт», Ростов-на-Дону \\ ${ }^{2}$ ФГАОУ ВО «Южный федеральный университет», Ростов-на-Дону
}

Поступила в редакцию 14.03.2019 г.

DOI: https://doi.org/10.17308/sorpchrom.2019.19/779

Найден оптимальный состав экстрагента, позволяющий извлекать полициклические ароматические углеводороды из донных отложений на уровне 80 \% и более. Обоснованы функции каждого растворителя, входящего в состав экстракционной смеси. Доказана возможность анализа малых количеств образца, а также использования небольших масс проб для разных типов донных отложений. По разработанной процедуре проведена оценка значений пределов обнаружения, которые составили от 0.1 до 3 нг/г сухого остатка донных отложений для отдельных веществ из группы ПАУ. Данная схема применена для анализа донных отложений реки Дон.

Ключевые слова: полициклические ароматические углеводороды (ПАУ), нефтепродукты, высокоэффективная жидкостная хроматография (ВЭЖХ), экстракция, донные отложения.

\section{Research of PAH extraction conditions from bottom sediments for determination by HPLC with fluorescence detection}

\author{
Kotova V.E. ${ }^{1}$, Andreev Yu.A. ${ }^{1,2}$ \\ ${ }^{1}$ FSBI «Hydrochemical Institute», Rostov-on-Don \\ ${ }^{2}$ FSAEI HE «Southern Federal University», Rostov-on-Don
}

\begin{abstract}
Polycyclic aromatic hydrocarbons (PAH) are the most dangerous compounds that produced by the high temperature combustion of fossil fuels and biomass, domestic and industrial wastes. PAH are included to priority pollutants list due to their carcinogenic and mutagenic properties. The aim of this work was to choose optimal extragent composition and appropriate sample mass for PAH determination in sediments. HPLC-analysis was carried out by Agilent Technologies 1260 Infinity with fluorescence detector; analytic column was ZORBAX Eclipse PAH. The necessity of solvents mixture using was shown. Solvents were acetone, hexane, methylene chloride and isooctane. Acetone was used as dehydrated agent, hexane was the main solvent for the followed analysis stages, methylene chloride was able to extract more PAH from the lipid matter and isooctane was able to prevent semivolatile components evaporation during concentrating. Recoveries were more than $50 \%$ for low weight PAH (except naphthalene) and more than $80 \%$ for high weight PAH. Different types of sediments (sludge and sand) were used for choosing sample mass for analysis. Several sample masses for each type of sediments were taken to estimate the optimum extraction scheme. Extracted PAH amounts were in proportion to organic matter in the composition of sediments of various types. Thus the sample mass of $2 \mathrm{~g}$ was considered to use for different types sediments analysis. Method detection limits ranged from 0.1 to $3.0 \mathrm{ng} \mathrm{g}^{-1}$ dry weight (d.w.). The applicability of the proposed method was evaluated by the PAH determination in sediments from 3 regions of River Don delta: Mertvy Donets, Perevolo-
\end{abstract}


ka, Peschany. Sediments were collected in April, May, July and October 2016. The summary of 15 PAH concentrations in the sediments ranged from 13 to $129 \mathrm{ng}$ g-1 d.w. for Peschany; from 61 to $340 \mathrm{ng}$ g-1 d.w. for Perevoloka and from 176 to $299 \mathrm{ng}$ g-1 d.w. for Mertvy Donets. Benzo[a]pyrene concentrations were from 0.5 to $11 \mathrm{ng}$ g-1 d.w. for Peschany; 4-31 ng g-1 d.w. for Perevoloka и 14-27 ng g-1 d.w. for Mertvy Donets. As a result of the study, a sample preparation scheme was developed, which allows determining PAH in sediments.

Keywords: polycyclic aromatic hydrocarbons (PAH), petroleum hydrocarbons, high performance liquid chromatography (HPLC), extraction, sediments.

\section{Введение}

Среди множества токсичных веществ, образующихся при производстве энергии сжиганием ископаемых видов топлива наиболее, опасными являются вещества группы полициклические ароматические углеводороды (ПАУ). Вследствие высокой канцерогенной и мутагенной активности ПАУ включены Агентствами по охране окружающей среды США и стран Европейского союза в списки наиболее опасных загрязняющих веществ почвы, воды и воздуха [1, 2].Среди нескольких сотен уже идентифицированных ПАУ выделяют группу из 16 соединений (которые называют приоритетными), являющихся наиболее опасными; об этих соединениях получено наибольшее количество информации по токсичности. В связи с высокой биологической активностью ПАУ к ним проявляется повышенный интерес химиков и экологов.

ПАУ широко распространены во всех объектах окружающей среды, это связано с тем, что они образуются при неполном сжигании различных видов топлива и мусора, следовательно, имеют многочисленные источники поступления. К ним относят [3] естественные источники горения (лесные пожары, вулканическая активность и др.) и антропогенные источники (сжигание ископаемого топлива, процессы газификации и сжигания угля, сжигание отходов и производство кокса, сажи, каменноугольной смолы, асфальта). Отдельный антропогенный источник поступления ПАУ - разлив разных видов топлива, включая нерафинированные (сырая нефть) и нефтепродукты.

Поскольку полициклические ароматические углеводороды обладают канцерогенными свойствами, содержание некоторых из них в воде нормируют. Предельно допустимые концентрации составляют для нафталина и бензо[а]пирена соответственно 10 мкг/дм ${ }^{3}$ и 5 нг/дм ${ }^{3}$ в питьевой воде, 10 мкг/дм ${ }^{3}$ и 10 нг/дм ${ }^{3}$ в воде хозяйственно-питьевого и культурно-бытового водопользования; 4 мкг/дм ${ }^{3}$ для нафталина в воде рыбохозяйственного значения $[4,5]$. Поскольку содержание загрязняющих веществ в донных отложениях российскими нормативными документами не регламентируется, для оценки загрязнения донных отложений могут использоваться «берлинские», «бранденбургские» и «голландские листы» [6, 7]: допустимая концентрация суммарного количества ПАУ в донных отложениях (и почве) - 1 нг/г сухого остатка (с.о.), а содержание, требующее вмешательства, - 40 нг/г с.о.

Целью данной работы является выбор оптимальных условий извлечения ПАУ для их определения в донных отложениях методом ВЭЖХ: состава экстракционной системы и массы образца.

\section{Эксперимент}

Стандарты и реактивы. В работе применяли образцы веществ индивидуальных ПАУ производства Supelco (США) с содержанием основного вещества 97.399.9\%: нафталин (Naph), аценафтен (Ace), флуорен (Fl), фенантрен (Phe), антрацен 
(An), флуорантен (Flu), пирен (Ру), бензо[а]антрацен (B[a]A), хризен (Chry), бензо[b]флуорантен (B[b]F), бензо[k]флуорантен $(\mathrm{B}[\mathrm{k}] \mathrm{F})$, бензо[a]пирен (B[a]P), дибензо[a,h]антрацен (DB[a,h]A), бензо[g,h,i] перилен (B[g,h,i]P), индено[1,2,3-cd]пирен $(\operatorname{In}[\mathrm{cd}] \mathrm{P})$. Использовали органические растворители отечественного производства квалификации не ниже «х.ч.» после очистки двукратной перегонкой (гексан, метиленхлорид, ацетон), а также импортного производства без дополнительной подготовки (изооктан, ацетонитрил). Градуировочные и рабочие растворы готовили последовательным разбавлением. Силикагель (Davisil (США), Grade 635, 60-100 меш, размер пор $60 \AA$ ) для колоночной хроматографии промывали в аппарате Сокслета метиленхлоридом в течение 6 ч и прокаливали в сушильном шкафу при $160^{\circ} \mathrm{C}$ в течение 4 ч.

Аппаратура и оборудование. Хроматографический анализ выполняли на жидкостном хроматографе Agilent Technologies 1260 Infinity со спектрофлуориметрическим детектором с аналитической колонкой ZORBAX Eclipse PAH размером $250 \times 3.0$ мм, неподвижная фаза - октадецилсилан $(\mathrm{C} 18)$, химически связанный с пористым силикагелем (размер зерна 5 мкм).

Методика. Способ определения ПАУ в донных отложениях заключался в извлечении смесью растворителей аналитов из образца; очистке полученных экстрактов водой; выделении методом колоночной хроматографии фракции ПАУ и хроматографическом анализе. Для этого пробу донных отложений массой около 2 г трижды экстрагировали посредством механического перемешивания последовательно порциями органических растворителей по $10 \mathrm{~cm}^{3}$; отфильтрованный через бумажный фильтр «синяя лента» экстракт очищали водой в делительных воронках (соотношение органической и водной фаз 3:10); водный слой повторно экстрагировали гексаном (соотношение органической и водной фаз 1:10). Объединенный экстракт осушали безводным сульфатом натрия и концентрировали путем отдувки очищенным воздухом при одновременном нагревании на водяной бане до $35-40^{\circ} \mathrm{C}$ до $1 \mathrm{~cm}^{3}$ в градуированных виалах с V-образным дном вместимостью $5 \mathrm{~cm}^{3}$. Далее сконцентрированный экстракт разделяли на фракции методом колоночной хроматографии на силикагеле (расход силикагеля 1.5 г), фракцию ПАУ элюировали $3 \mathrm{~cm}^{3}$ смеси гексанметиленхлорид (1:1 по объему), концентрировали до $1 \mathrm{~cm}^{3}$ в градуированных виалах и анализировали методом ВЭЖХ.

\section{Обсуждение результатов}

Выбор состава экстрагента для извлечения ПАУ из донных отложений. Известны способы извлечения ПАУ, в которых для экстракции обычно применяют гексан, хлороформ или смеси растворителей [8]. Учитывая специфику объекта анализа, в данной работе при выборе состава экстрагента предусматривали разные функции растворителей в составе смеси: гексан (неполярной природы, обладающий большим сродством к нефтепродуктам), метиленхлорид (более легкокипящий полярный аналог хлороформа, с сильной растворяющей способностью, в том числе жироподобных веществ), ацетон (смешивающийся с водой и другими органическими растворителями), изооктан (малолетучий, высококипящий, предотвращающий испарение легкокипящих извлекаемых компонентов пробы).

При анализе объектов, содержащих воду, применяются различные способы ее связывания [9-12]. Наиболее распространенный - применение для обезвоживания прокаленного сульфата натрия. Из альтернативных способов удаления мешающей анализу воды можно привести высушивание образцов посредством лиофилизации, 
при комнатной температуре (или за счет нагревания), а также гомогенное связывание водной фазы.

Наиболее часто используемый способ обезвоживания проб донных отложений/почвы добавлением безводного сульфата натрия имеет ряд недостатков. Для анализа используется масса образца около 10 г и более, при этом масса добавляемого сульфата натрия должна в 2-3 раза превышать массу образца, в таком случае для экстракции требуется огромное количество особо чистых и дорогих растворителей (от десятков до сотен миллилитров). Использование большого количества растворителя недостаточной степени очистки при концентрировании экстрактов приведет к появлению пиков мешающих веществ.

В случае анализа даже небольших масс образцов с высоким значением влажности (например, пелитовых илов, влажность которых достигает 70-90\%), для их полного обезвоживания необходим достаточно большой избыток сульфата натрия и соответственно бо́льшее количество растворителя, чтобы обеспечить «покрытие» образца жидкостью и последующее количественное отделение экстракта. При связывании воды сульфат натрия часто затвердевает, образуя включения, содержащие анализируемый образец, что дополнительно затрудняет доступ растворителя к пробе донных отложений. Измельчение или разрушение подобных твердых образований влечет за собой дополнительное загрязнение образцов, в том числе перекрестное, при котором становится невозможным определять единицы нанограммов аналитов.

В соответствии с данными авторов [12] провели эксперимент по извлечению ПАУ метиленхлоридом из лиофилизированных и естественной влажности донных отложений (рис. 1), в результате которого доказана необходимость обезвоживания проб для их анализа - более полное извлечение получено для лиофилизированных образцов. Этим этапом обоснована необходимость удаления воды, присутствующей в донных отложениях.

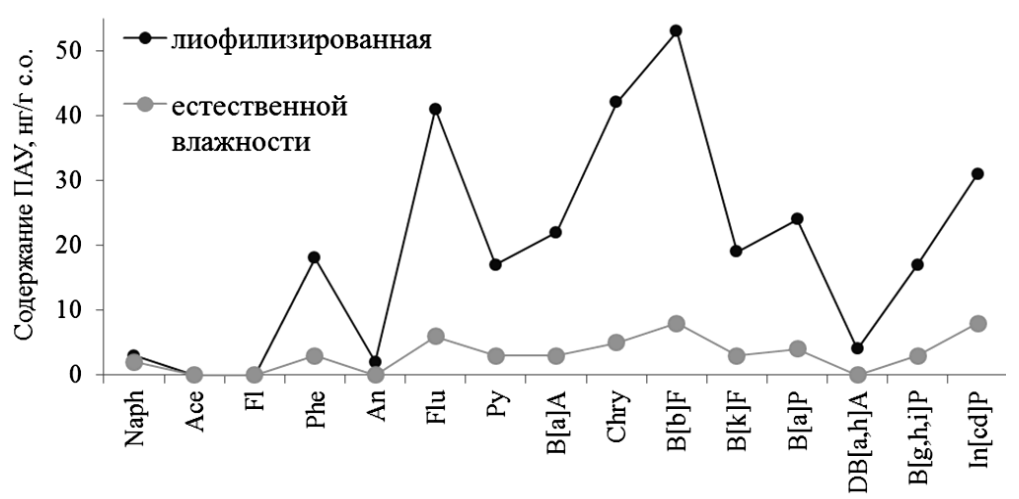

Рис. 1. Сравнение результатов определения ПАУ

во влажных (естественной влажности) и лиофилизированных донных отложениях при извлечении метиленхлоридом

Сушка на воздухе увеличивает потенциальные потери легколетучих ПАУ, а также их окисление, перекрестное загрязнение при сушке нескольких образцов и, главное, воздействие загрязнителей воздуха, в то время как сушка вымораживанием требует длительного времени, дорогостоящего специализированного оборудования.

Поэтому при анализе проб естественной влажности в качестве обезвоживающего агента далее использовали ацетон, порции которого объединяли с последующими экстрактами.

На данном этапе исследования варьировали соотношение и кратность обработки ацетоном, состав экстрагента для ПАУ оставался постоянным - гексан- 
метиленхлорид (1:1 по объему). При установлении числа экстракций для полного связывания воды проводили параллельное извлечение ПАУ одной, двумя и тремя порциями ацетона по $10 \mathrm{~cm}^{3}$ (табл. 1 столбцы 1-3 соответственно) и еще двумя порциями по $10 \mathrm{~cm}^{3}$ смеси ацетон-гексан-метиленхлорид (2:1:1 по объему) из проб донных отложений естественной влажности.

Таблица 1. Сравнение результатов определения ПАУ во влажных донных отложениях при разных объемах ацетона $(\mathrm{n}=4, \mathrm{P}=0.95)$

\begin{tabular}{|c|c|c|c|}
\hline \multirow{2}{*}{ Вещество } & \multicolumn{3}{|c|}{ Массовые доли ПАУ, нг/г с.о., } \\
& для разной кратности обработки ацетоном при обезвоживании \\
\cline { 2 - 4 } & 1-кратная & 2-кратная & 3-кратная \\
\hline Naph & $6.5(0.1)^{*}$ & $7.9(0.1)$ & $7.0(0.3)$ \\
\hline Ace & $0.8(0.1)$ & $0.9(0.2)$ & $0.7(0.3)$ \\
\hline Fl & $2.7(0.03)$ & $2.9(0.08)$ & $2.6(0.2)$ \\
\hline Phe & $19(0.05)$ & $20(0.1)$ & $18(0.2)$ \\
\hline An & $2.4(0.1)$ & $2.9(0.05)$ & $2.2(0.2)$ \\
\hline Flu & $37(0.1)$ & $38(0.1)$ & $29(0.1)$ \\
\hline Py & $24(0.1)$ & $25(0.1)$ & $19(0.1)$ \\
\hline B[a]A & $16(0.1)$ & $18(0.1)$ & $13(0.2)$ \\
\hline Chry & $16(0.2)$ & $18(0.1)$ & $14(0.2)$ \\
\hline B[b]F & $23(0.2)$ & $31(0.4)$ & $23(0.1)$ \\
\hline B[k]F & $11(0.1)$ & $12(0.1)$ & $8.6(0.2)$ \\
\hline B[a]P & $15(0.2)$ & $16(0.2)$ & $11(0.2)$ \\
\hline DB[a,h]A & $1.9(0.2)$ & $2.2(0.05)$ & $1.6(0.2)$ \\
\hline B[g,h,i]P & $14(0.04)$ & $18(0.1)$ & $13(0.1)$ \\
\hline In[cd]P & $16(0.08)$ & $16(0.2)$ & $11(0.3)$ \\
\hline
\end{tabular}

*здесь и далее в скобках приведены значения относительного стандартного отклонения

По результатам таблицы 1 видно, что наименьшие массовые доли ПАУ получены при экстракции тремя порциями ацетона, для двух других вариантов найдены близкие значения. Таким образом, обосновано применение для обезвоживания одной экстракции ацетоном как наиболее экономичного по расходу растворителей способа.

Далее для изучения эффективности извлечения ПАУ провели серию экспериментов по варьированию состава экстракционной смеси (табл. 2). В качестве извлекающего агента рассматривали гексан, гексан-метиленхлорид (1:1 по объему) и гексан-метиленхлорид-изооктан (2:2:1 по объему). Состав экстракционных смесей:

- способ 1: $10 \mathrm{~cm}^{3}$ ацетона; $10 \mathrm{~cm}^{3}$ смеси ацетон-гексан (1:1 по объему); $10 \mathrm{~cm}^{3}$ смеси ацетон-гексан (1:1 по объему);

- способ 2: $10 \mathrm{~cm}^{3}$ ацетона; $10 \mathrm{~cm}^{3}$ смеси ацетон-гексан-метиленхлорид (2:1:1 по объему); $10 \mathrm{~cm}^{3}$ смеси ацетон-гексан-метиленхлорид (2:1:1 по объему);

- способ 3: $10 \mathrm{~cm}^{3}$ ацетона; $10 \mathrm{~cm}^{3}$ смеси ацетон-гексан-метиленхлорид (2:1:1 по объему); $10 \mathrm{~cm}^{3}$ смеси ацетон-гексан-метиленхлорид-изооктан (5:2:2:1 по объему).

Изучение степеней извлечения проводили методом «Введено-найдено», обобщенные результаты представлены на рисунке 2. При проведении экстракции по способу 1 получены самые низкие значения степеней извлечения (20-70\% для разных веществ). По способу 2 (при добавлении метиленхлорида) извлечение увеличивается от 25 до $80 \%$, что можно объяснить его лучшей способностью извлекать ПАУ из липидных составляющих донных отложений. В способе 3 используется изооктан, имеющий бо́льшую температуру кипения по сравнению с используемыми в работе растворителями, что позволяет снизить потерю легких ПАУ при концентри- 
ровании и достичь значения степеней извлечения $50 \%$ и более для легких ПАУ (кроме нафталина), 80\% и более для тяжелых ПАУ $[13,14]$.

Таблица 2. Сравнение результатов определения ПАУ при различных составах экстракционной системы

\begin{tabular}{|c|c|c|c|}
\hline \multirow{2}{*}{ Вещество } & \multicolumn{3}{|c|}{ Массовые доли ПАУ, нг/г с.о., при различных составах экстракционной системы } \\
\cline { 2 - 4 } & Способ 1 & Способ 2 & Способ 3 \\
\hline Naph & $3.2(0.1)$ & $3.2(0.2)$ & $4.5(0.2)$ \\
\hline Ace & $0.2(0.2)$ & $0.3(0.2)$ & $0.5(0.1)$ \\
\hline Fl & $0.6(0.3)$ & $0.7(0.1)$ & $0.7(0.1)$ \\
\hline Phe & $6.6(0.1)$ & $6.1(0.2)$ & $4.9(0.2)$ \\
\hline An & $0.4(0.2)$ & $0.4(0.1)$ & $0.4(0.2)$ \\
\hline Flu & $4.1(0.2)$ & $3.2(0.2)$ & $4.0(0.2)$ \\
\hline Py & $3.1(0.1)$ & $3.1(0.1)$ & $3.2(0.2)$ \\
\hline B[a]A & $1.4(0.1)$ & $1.4(0.3)$ & $1.8(0.3)$ \\
\hline Chry & $2.3(0.1)$ & $2.2(0.2)$ & $2.4(0.3)$ \\
\hline B[b]F & $2.5(0.2)$ & $2.5(0.2)$ & $3.1(0.2)$ \\
\hline B[k]F & $1.1(0.2)$ & $1.1(0.2)$ & $1.4(0.2)$ \\
\hline B[a]P & $1.3(0.2)$ & $1.7(0.6)$ & $0.3(0.3)$ \\
\hline DB[a,h]A & $0.2(0.1)$ & $0.2(0.3)$ & $2.0(0.3)$ \\
\hline B[g,h,i]P & $1.6(0.1)$ & $1.6(0.2)$ & $1.7(0.3)$ \\
\hline In[cd]P & $1.1(0.2)$ & $1.2(0.3)$ & \\
\hline
\end{tabular}

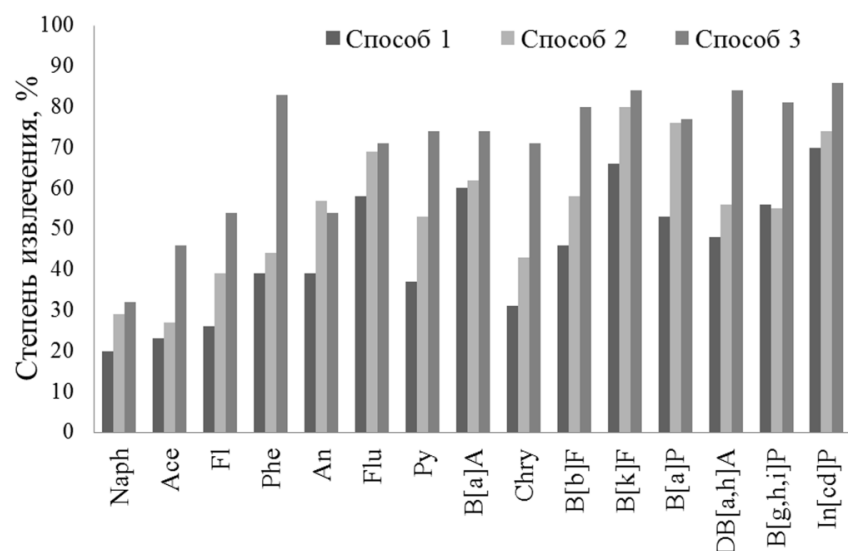

Рис. 2. Степени извлечения ПАУ при использовании экстракционных систем различного состава

Таким образом, обоснован выбор состава экстракционной смеси для извлечения ПАУ, позволяющей получать высокие степени извлечения для тяжелых представителей и приемлемые для низкомолекулярных соединений.

Выбор массы донных отложений для определения ПАУ. Немаловажным аспектом способа анализа при разработке методики определения ПАУ в донных отложениях является выбор необходимой навески, достаточной для получения надежного и достоверного результата. Выбор массы донных отложений для анализа осложнен, с одной стороны, необходимостью достижения высокой чувствительности определения (которая увеличивается прямо пропорционально изменению навески образца), с другой же стороны, ограничен увеличением количества мешающей анализу воды. Уменьшение навески образца ведет к возможности полного удаления воды из донных отложений, способствует экономии экстрагентов и реактивов без потери инструментальной чувствительности. 
Эксперименты проводили на донных отложениях разных типов естественной влажности (60-80\%): мелкоалевритовых илах (далее - илистых донных отложений) и мелкозернистых с примесью среднезернистых песках (далее - песчаных донных отложений). Поскольку илистые донные отложения способны сорбировать бо́льшее количество органических веществ по сравнению с песчаными, для исследования использовали меньшие навески илистых (проба 1) и бо́льшие навески песчаных (проба 2) донных отложений. В таблице 3 представлены результаты определения ПАУ в пробах без добавок.

Таблица 3. Сравнение извлечения ПАУ из разных масс донных отложений $(\mathrm{n}=4$, $\mathrm{P}=0.95)$

\begin{tabular}{|c|c|c|c|c|}
\hline \multirow{3}{*}{ Вещество } & \multicolumn{2}{|c|}{ Проба 1 $(\omega=72 \%)$} & \multicolumn{2}{|c|}{ Проба 2 $(\omega=64 \%)$} \\
\cline { 2 - 5 } & 1 г & 2 г & 2 г & 4 г \\
\cline { 2 - 5 } & $\begin{array}{c}\text { Массовая доля, } \\
\text { нг/г с.о. }\end{array}$ & $\begin{array}{c}\text { Массовая доля, } \\
\text { нг/г с.о. }\end{array}$ & $\begin{array}{c}\text { Массовая доля, } \\
\text { нг/г с.о. }\end{array}$ & $\begin{array}{c}\text { Массовая доля, } \\
\text { нг/г с.о. }\end{array}$ \\
\hline Naph & $3.1(0.2)$ & $3.6(0.1)$ & $3.0(0.2)$ & $3.8(0.1)$ \\
\hline Ace & $0.23(0.4)$ & $0.24(0.2)$ & $0.46(0.3)$ & $0.56(0.4)$ \\
\hline Fl & $0.69(0.3)$ & $0.74(0.4)$ & $1.1(0.3)$ & $0.97(0.4)$ \\
\hline Phe & $24(0.3)$ & $26(0.2)$ & $9.8(0.2)$ & $8.3(0.1)$ \\
\hline An & $2.6(0.4)$ & $2.8(0.3)$ & $1.0(0.2)$ & $0.80(0.2)$ \\
\hline Flu & $56(0.3)$ & $57(0.2)$ & $9.4(0.3)$ & $7.2(0.1)$ \\
\hline Py & $22(0.2)$ & $24(0.1)$ & $6.1(0.1)$ & $4.5(0.1)$ \\
\hline B[a]A & $26(0.2)$ & $28(0.1)$ & $3.1(0.4)$ & $3.0(0.3)$ \\
\hline Chry & $48(0.3)$ & $50(0.2)$ & $2.3(0.3)$ & $4.1(0.2)$ \\
\hline B[b]F & $72(0.2)$ & $74(0.3)$ & $5.3(0.1)$ & $6.9(0.1)$ \\
\hline B[k]F & $26(0.1)$ & $26(0.2)$ & $2.3(0.2)$ & $2.0(0.3)$ \\
\hline B[a]P & $25(0.2)$ & $27(0.2)$ & $3.6(0.2)$ & $3.1(0.1)$ \\
\hline DB[a,h]A & $5.6(0.2)$ & $5.2(0.1)$ & $0.43(0.3)$ & $0.65(0.3)$ \\
\hline B[g,h,i]P & $22(0.1)$ & $24(0.2)$ & $2.8(0.2)$ & $2.1(0.2)$ \\
\hline In[cd]P & $36(0.1)$ & $39(0.3)$ & $2.8(0.2)$ & $2.7(0.1)$ \\
\hline
\end{tabular}

На рисунке 3 представлены объединенные хроматограммы экстрактов, полученных из 1 и 2 г илистых (а) и 2 и 4 г песчаных донных отложений (б).

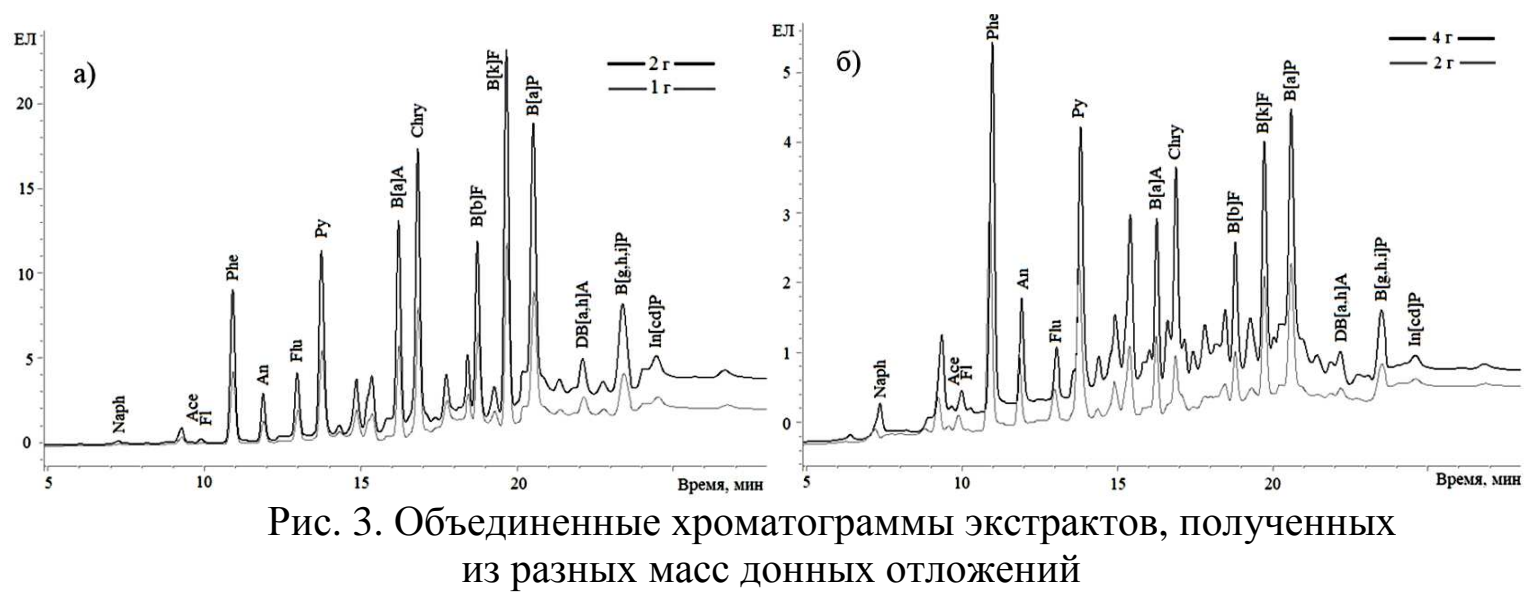

Результаты, полученные при анализе илистых и песчаных донных отложений, изменяются пропорционально доле органической фракции в составе донных отложений разных типов - в меньшей массе илистых донных отложений, с бо́льшим содержанием остатков липидных веществ, абсолютное содержание ПАУ выше, чем в песчаных донных отложениях. Следует отметить, что проба 1 характеризуется низ- 
ким содержанием сухого вещества (28\%), но за счет высокой доли органического вещества для нее достаточным оказалось использование навески в 1 г. Проба 2 содержит бо́льшее, чем проба 1 , количество сухого вещества $(36 \%)$, но за счет низкой доли органического вещества в более крупных частицах песка навеска 2 г оказалась достаточной, чтобы извлечь приемлемое для получения надежного результата количество ПАУ.

Таким образом, показана возможность отбора малых навесок проб донных отложений при определении ПАУ для разных типов донных отложений (или в случае смешанных типов). Для повышения представительности пробы выбрана масса образца, равная 2 г.

По предложенной процедуре $[13,15]$ выполнена серия измерений для оценки пределов обнаружения. Определения проводили методом «Введено-найдено». Значения пределов обнаружения составили: 0.1 нг/г с.о. для антрацена; 0.2 нг/Г с.о. для бензо[а]антрацена, бензо[а]пирена, дибензо[а,h]антрацена; 0.3 нг/г с.о. для аценафтена, бензо[k]флуорантена, бензо[g,h,i]перилена; 0.4 нг/Г с.о. для хризена; 0.5 нг/г с.о. для флуорена; 0.6 нг/г с.о. для пирена, бензо[b]флуорантена; 1 нг/г с.о. для фенантрена и индено[1,2,3-cd]пирена; 2 нг/г с.о. для флуорантена; 3 нг/г с.о. для нафталина.

Коэффициенты вариации для изученного диапазона составили 0.03-0.4 для низких концентраций (на уровне единиц нанограммов на 1 г сухого остатка) и 0.010.04 для высоких концентраций (сотни нанограммов на 1 г сухого остатка).

Апробация разработанного способа определения ПАУ на реальных объектах. Предложенная схема применена для анализа донных отложений трех рукавов устьевого участка р. Дон: Мертвый Донец, Песчаный и Переволока [16]. Отбор проводили в апреле, мае, июле и октябре 2016 г. Донные отложения рукавов Мертвого Донца и Переволоки представлены алевритовыми илами (глубины отбора 2-6 м); донные отложения рукава Песчаного выражены мелкозернистыми песками с примесью среднезернистых (глубина отбора 2-5 м). Хроматограммы экстрактов донных отложений изучаемых объектов приведены на рисунках 4-6.

Хроматограммы демонстрируют различное количество присутствующих ПАУ в зависимости от типа донных отложений и от доли содержащегося в них органического вещества. Результаты данного исследования показали, что ПАУ присутствуют во всех образцах донных отложений изученного участка р. Дон в интервале суммарных содержаний: 13-129 нг/г с.о. для Песчаного; 61-340 нг/г с.о. для Переволоки и 176-299 нг/г с.о. для Мертвого Донца. Массовые доли бензо[а]пирена составили 0.5-11 нг/г с.о. для Песчаного; 4-31 нг/г с.о. для Переволоки и 14-27 нг/г с.о. для Мертвого Донца.

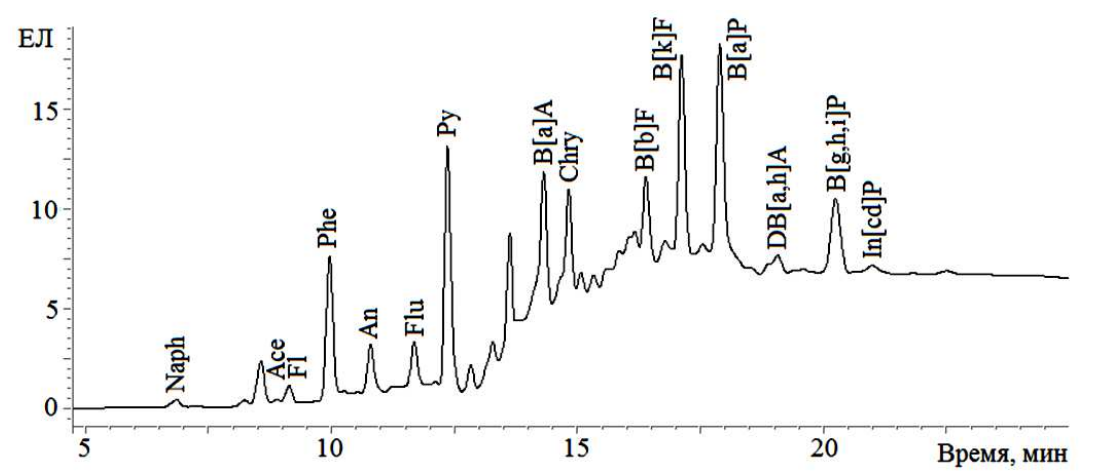

Рис. 4. Хроматограмма экстракта донных отложений, отобранных из рукава Мертвый Донец в июле 2016 г. 


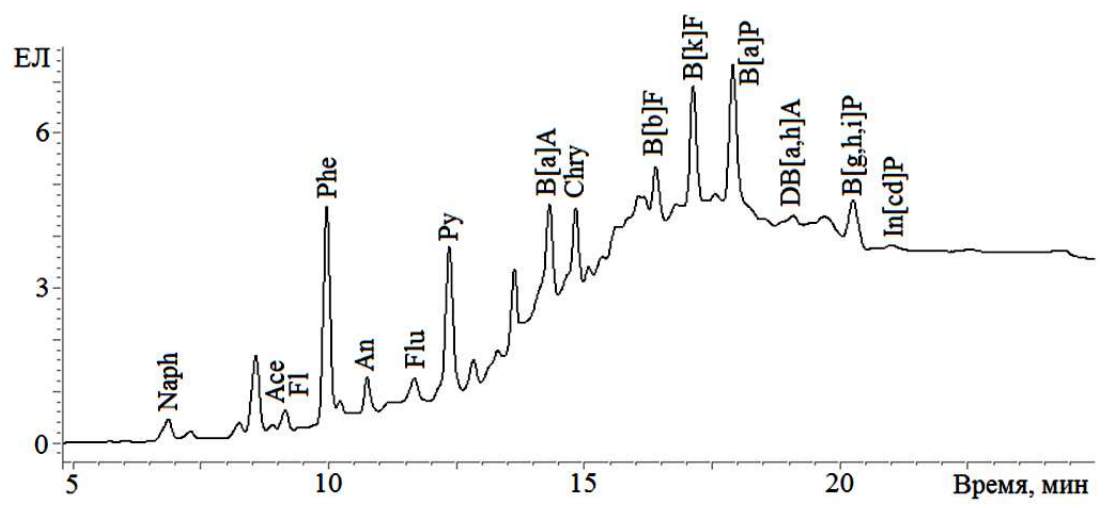

Рис. 5. Хроматограмма экстракта донных отложений, отобранных из рукава Переволока в мае 2016 г.

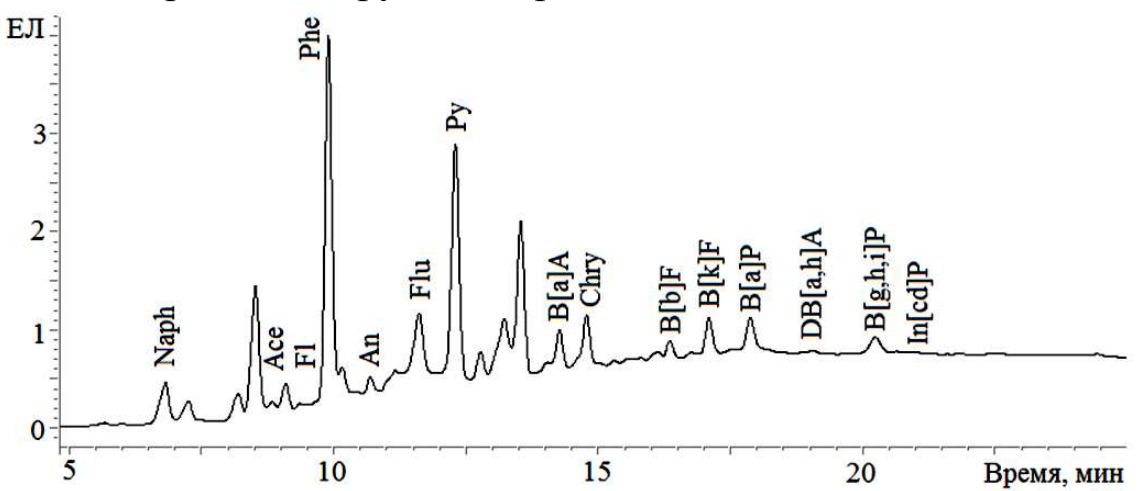

Рис. 6. Хроматограмма экстракта донных отложений, отобранных из рукава Песчаный в апреле 2016 г.

\section{Заключение}

Отмечено, что при последовательной обработке проб донных отложений смесью растворителей (ацетон-гексан-метиленхлорид-изооктан) в качестве экстрагента достигается достаточное извлечение ПАУ, позволяющее надежно измерять их содержание в природных объектах. Показана возможность использования для анализа массы донных отложений разного типа, равной 2 г, без потери чувствительности анализа. Пределы обнаружения изучаемых веществ по разработанной процедуре составили 0.1-3 нг/г с.о.

\section{Список литературы}

1 Крылов А., Лопушанская Е., Александрова А., Конопелько Л. // Аналитика. 2012. T. 3. № 4. С. 6-16.

2 Кузнецов А.Н., Федоров Ю.А. Нефтяное загрязнение в водных экосистемах. Закономерности естественной трансформации. Саарбрюкен, LAP Lambert Academic Publishing. 2011. $196 \mathrm{c}$.

3 McCready S., Slee D.J., Birch G.F., Taylor S.E. // Mar. Pollut. Bull. 2000. Vol. 40. No 11. pp. 999-1006.

4 ГН 2.1.5.1315-03. допустимые концентрации (ПДК) химиче- ских веществ в воде водных объектов хозяйственно-питьевого и культурно-бытового водопользования. В ред. Дополнений и изменений № 1, утв. Постановлением Главного государственного санитарного врача РФ от 28.09.2007 г. № 75, Постановления Главного государственного санитарного врача РФ от 28.09.2007 г. № 77, Изменений № 2, утв. Постановлением Главного государственного санитарного врача РФ от 16.09.2013 г. № 49, Постановлений Главного государственного санитарного врача РФ от 30.08.2016 г. № 147, от 13.07.2017 г. № 97. Зарегистрировано в Минюсте России 19.05.2003 г. 
№ 4550. Режим доступа: http://docs.cntd.ru/document/901862249 (дата обращения: 26.12.2018 г.).

5 Приказ Минсельхоза России от 13.12.2016 г. № 552 «Об утверждении нормативов качества воды водных объектов рыбохозяйственного значения, в том числе нормативов предельно допустимых концентраций вредных веществ в водах водных объектов рыбохозяйственного значения». Режим доступа: http://docs.cntd.ru/document /420389120 (дата обращения: 26.12.2018 г.).

6Das neue BundesBodenschutzgesetz. («Берлинские листы», «Бранденбургские листы»). Режим доступа: https://www.gesetze-iminternet.de/bbodschg/BBodSchG.pdf (дата обращения: 26.12.2018 г.).

7 Leidraad Bodemsanering (1994): Mitteilung des Rijksinstituut voor Volksgezondheit en Milieuhygiene. («Голландские листы»). Режим доступа:

https://lfu.brandenburg.de/cms/media.php/lbm1. a.3310.de/lua_bd48.pdf (дата обращения: 26.12.2018 г.).

8 Суздорф А.Р., Морозов С.В., Кузубова Л.И., Аншиц Н.Н., Аншиц А.Г. // Химия в интересах устойчивого развития. 1994. № 2. C. 511-540.

\section{References}

1 Krylov A., Lopushanskaya E., Aleksandrova A., Konopel'ko L., Analitika, 2012, Vol. 3, No 4, pp. 6-16.

2 Kuznetsov A.N., Fedorov Yu.A. Oil pollution in aquatic ecosystems. Patterns of natural transformation. Saarbrucken, LAP Lambert Academic Publishing, 2011, 196 p.

3 McCready S., Slee D.J., Birch G.F., Taylor S.E., Mar. Pollut. Bull., 2000, Vol. 40, No 11, pp. 999-1006.

4 GN 2.1.5.1315-03. Predel'no-dopustimye kontsentratsii (PDK) khimicheskikh veshchestv $\mathrm{v}$ vode vodnykh ob"ektov khozyaistvennopit'evogo i kul'turno-bytovogo vodopol'zovaniya. V red. Dopolnenii i izmenenii No 1 , utv. Postanovleniem Glavnogo gosudarstvennogo sanitarnogo vracha RF ot 28.09.2007 g. No 75, Postanovleniya Glavnogo gosudarstvennogo sanitarnogo vracha RF ot 28.09.2007 g. No 77, Izmenenii No 2, utv. Postanovleniem Glavnogo gosudarstvennogo sanitarnogo vracha $\mathrm{RF}$ ot 16.09.2013 g. No 49, Postanovlenii Glavnogo gosudarstvennogo sanitarnogo vracha RF ot
9 Auer W., Malissa H. // Anal. Chim. Acta. 1990. Vol. 231. pp. 451-457.

10 Leite N.F., Peralta-Zamora P., Grassi M.T. // J. Chromatogr. A. 2008. Vol. 1192. Is. 2. pp. 273-281.

11 Araghi P.E., Bastami K.D., Rahmanpoor S. // Mar. Pollut. Bull. 2014. Vol. 89. Is. 12. pp. 494-498.

12 Capangpangan M.B., Suffet I.H. // J. Chromatogr. A. 1996. Vol. 738. pp. 253-264.

13 Котова В.Е., Андреев Ю.А., Черновьянц М.С. // Сорбиионные и хроматографические прочессы. 2016. Т. 16. № 6. С. 885892.

14 Котова В.Е., Андреев Ю.А., Черновьянц М.С. // «Третий съезд аналитиков России», тезисы докладов, 8-13 октября 2017 г., M., 2017, С. 331. Режим доступа: http://www.wssanalytchem.org/car2017/Publica tions/2017-Abstracts.pdf (дата обращения: 26.12.2018).

15 Котова В.Е., Андреев Ю.А. Патент РФ, № 2646402, 2018.

16 Котова В.Е., Андреев Ю.А. // «Системы обеспечения техносферной безопасности», материалы V Всероссийской научной конференции и школы для молодых ученых (с международным участием), 5-6 октября 2018 г. Таганрог. 2018. С. 131-133.

30.08.2016 g. No 147, ot 13.07.2017 g. No 97. Zaregistrirovano v Minyuste Rossii 19.05.2003 g. No 4550. Available at: http://docs.cntd.ru/document/901862249 (accessed 26 December 2018).

5 Prikaz Minsel'khoza Rossii ot 13.12.2016 g. No 552 «Ob utverzhdenii normativov kachestva vody vodnykh ob"ektov rybokhozyaistvennogo znacheniya, $\mathrm{v}$ tom chisle normativov predel'no dopustimykh kontsentratsii vrednykh veshchestv v vodakh vodnykh ob"ektov rybokhozyaistvennogo znacheniya». Available at: http://docs.cntd.ru/document/420389120 (accessed 26 December 2018).

6 Das neue BundesBodenschutzgesetz. («Berlinskie listy», «Brandenburgskie listy»). Available at: https://www.gesetze-iminternet.de/bbodschg/BBodSchG.pdf (accessed 26 December 2018).

7 Leidraad Bodemsanering (1994): Mitteilung des Rijksinstituut voor Volksgezondheit en Milieuhygiene. («Gollandskie listy»). Available at: https://lfu.brandenburg.de/cms/media.php/lbm1. 
a.3310.de/lua_bd48.pdf (accessed 26 December 2018).

8 Suzdorf A.R., Morozov S.V., Kuzubova L.I., Anshits N.N., Anshits A.G., Khimiya $v$ interesakh ustoichivogo razvitiya, 1994, No 2, pp. 511-540.

9 Auer W., Malissa H., Anal. Chim. Acta, 1990, Vol. 231, pp. 451-457.

10 Leite N.F., Peralta-Zamora P., Grassi M.T., J. Chromatogr. A, 2008, Vol. 1192, I. 2, pp. 273-281.

11 Araghi P.E., Bastami K.D., Rahmanpoor S., Mar. Pollut. Bull., 2014, Vol. 89, I. 1-2, pp. 494-498.

12 Capangpangan M.B.,

Suffet I.H., J. Chromatogr. A, 1996, Vol. 738, pp. 253-264.

13 Kotova V.E., Andreev Yu.A., Chernov'yants M.S., Sorbtsionnye i khromatografi-

Котова Валентина Евгеньевна - научный сотрудник, ФГБУ «Гидрохимический институт», Ростов-на-Дону

Андреев Юрий Александрович - заведующий лабораторией методов и технических средств анализа вод, ФГБУ «Гидрохимический институт», Ростов-на-Дону; доцент, к.х.н., ФГАОУ ВО «Южный федеральный университет», Ростов-на-Дону cheskie protsessy, 2016, Vol. 16, No 6, pp. 885892.

14 Kotova V.E., Andreev Yu.A., Chernov'yants M.S., «Third Congress of Russian Analysts», Proceedings, October 8-13, 2017, Moscow, pp. 331. Available at: http://www.wssanalytchem.org/car2017/Publica tions/2017-Abstracts.pdf (accessed 26 December 2018).

15 Kotova V.E., Andreev Yu.A. Patent RF, No 2646402, 2018.

16. Kotova V.E., Andreev Yu.A., «Technosphere safety systems», Proceedings of the V All-Russian Scientific Conference and school for young researchers (with the international participation), October 5-6, 2018, Taganrog, pp. 131-133.

Kotova Valentina E. - researcher, FSBI «Hydrochemical Institute», Rostov-on-Don, e-mail: Valentina.E.Kotova@gmail.com

Andreev Yury A. - head of laboratory of methods and technical facilities of water analysis, FSBI «Hydrochemical Institute», Rostov-on-Don; associate prof., Ph. D. (chemistry), FSAEI HE «Southern Federal University», Rostov-on-Don, e-mail: y.a.andreev@gmail.com 